\title{
Next Generation Nuclear Plant System Requirements Manual
}

March 2009

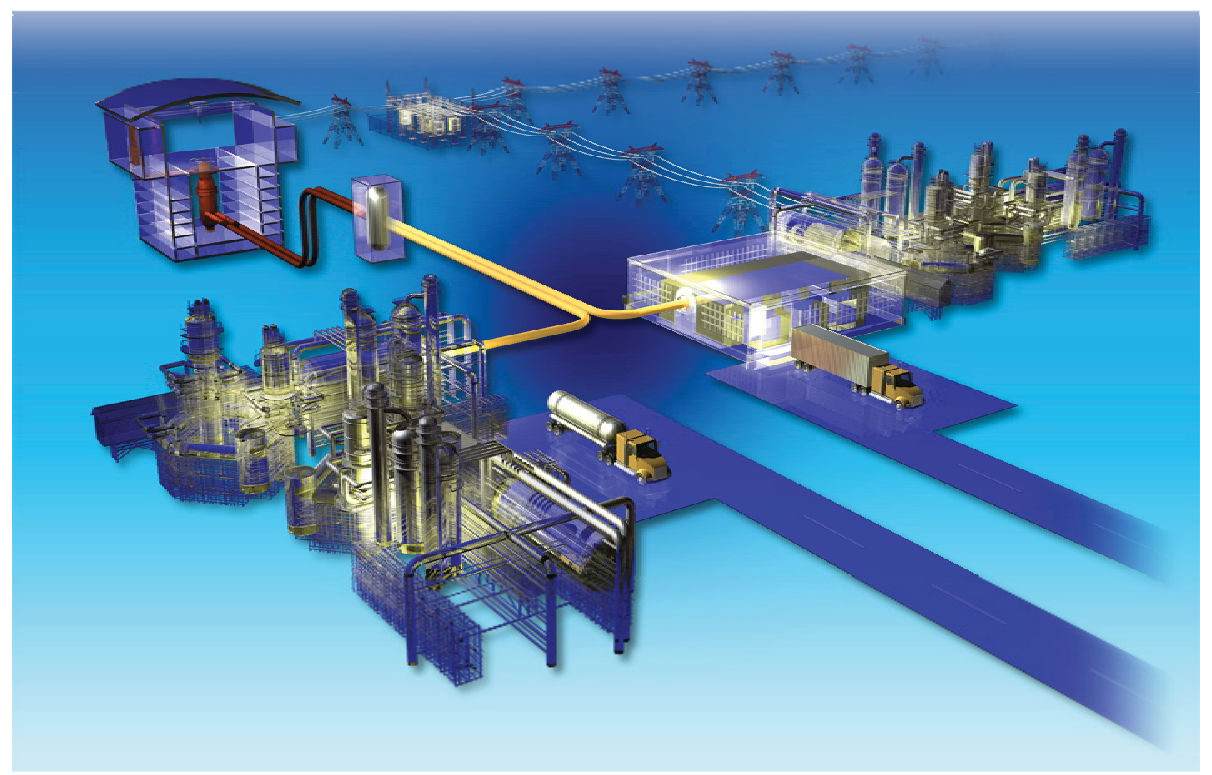

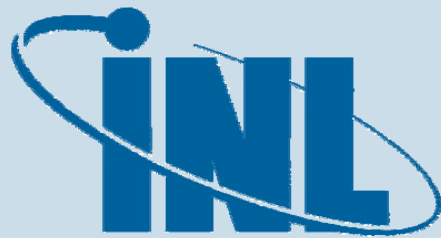

Idaho National Laboratory
The INL is a U.S. Department of Energy National Laboratory operated by Battelle Energy Alliance 


\section{DISCLAIMER}

This information was prepared as an account of work sponsored by an agency of the U.S. Government. Neither the U.S. Government nor any agency thereof, nor any of their employees, makes any warranty, expressed or implied, or assumes any legal liability or responsibility for the accuracy, completeness, or usefulness, of any information, apparatus, product, or process disclosed, or represents that its use would not infringe privately owned rights. References herein to any specific commercial product, process, or service by trade name, trade mark, manufacturer, or otherwise, does not necessarily constitute or imply its endorsement, recommendation, or favoring by the U.S. Government or any agency thereof. The views and opinions of authors expressed herein do not necessarily state or reflect those of the U.S. Government or any agency thereof. 
INL/EXT-07-12999

Rev. 2

\title{
Next Generation Nuclear Plant System Requirements Manual
}

March 2009

\author{
Idaho National Laboratory \\ Next Generation Nuclear Plant Project \\ Idaho Falls, Idaho 83415
}

Prepared for the U.S. Department of Energy Office of Nuclear Energy Under DOE Idaho Operations Office

Contract DE-AC07-05ID14517 



\title{
Next Generation Nuclear Plant (NGNP) Project
}

\section{Next Generation Nuclear Plant System Requirements Manual}

\author{
INL/EXT-07-12999 \\ Revision 2
}

March 2009

Approved by:

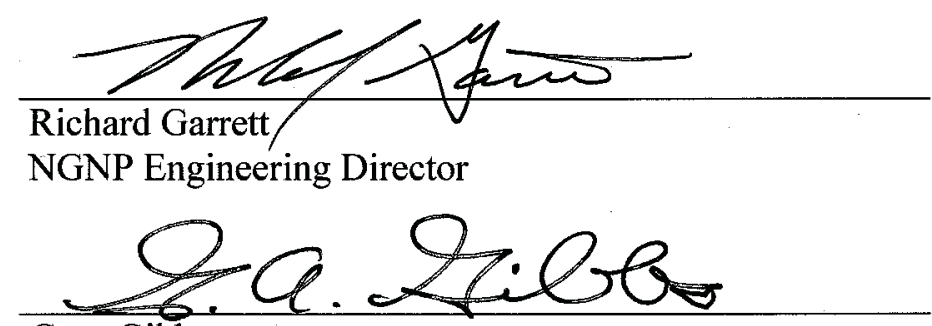

Greg Gibbs

NGNP Project Director

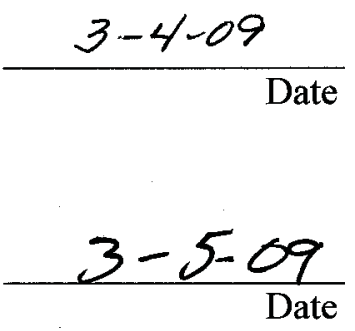





\section{CONTENTS}

ACRONYMS viii

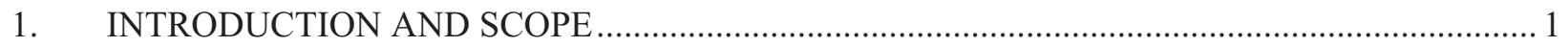

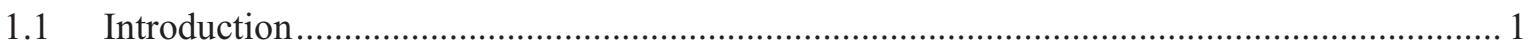

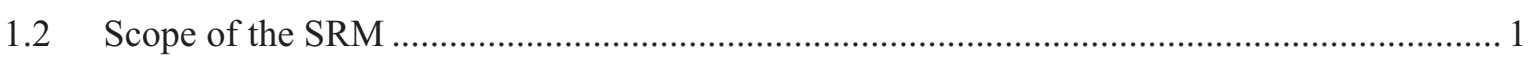

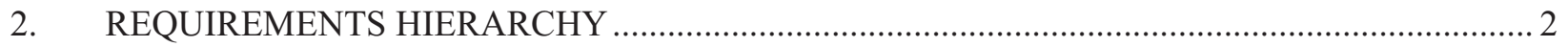

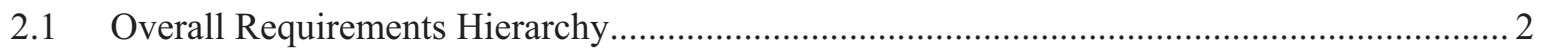

2.2 Conceptual Design Requirements Process ..................................................................... 3

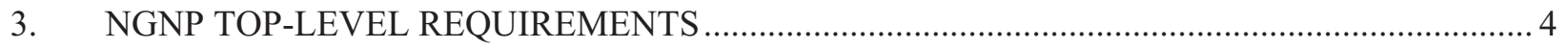

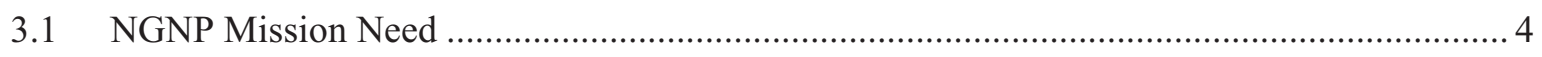

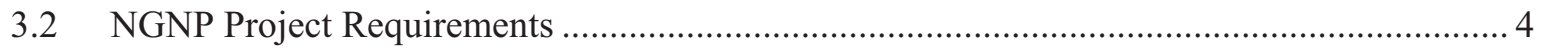

3.2.1 NGNP Project Requirements at Pre-Conceptual Design ......................................... 4

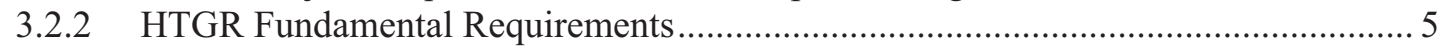

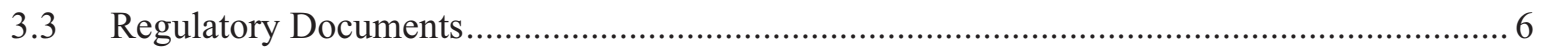

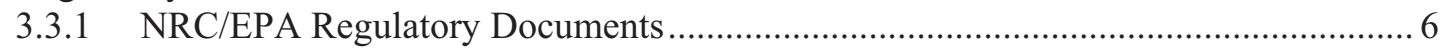

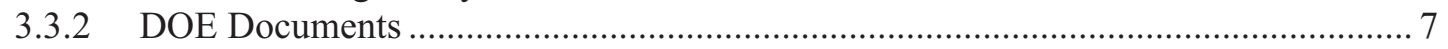

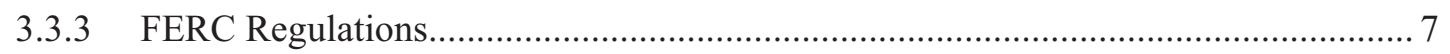

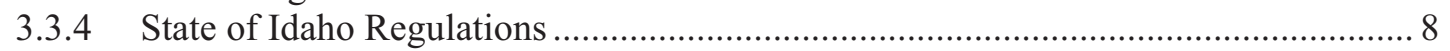

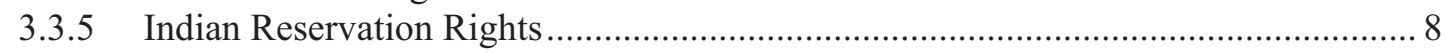

4. FUNCTIONAL, OPERATIONAL, AND TECHNICAL REQUIREMENTS ................................ 8

4.1 Requirements Applicable to Multiple Systems, Buildings and Structures ............................ 8

4.1.1 System Configuration and Essential Features Requirements.................................... 8

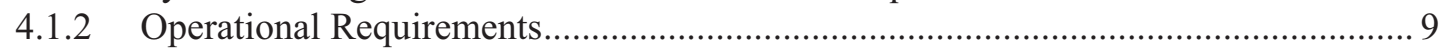

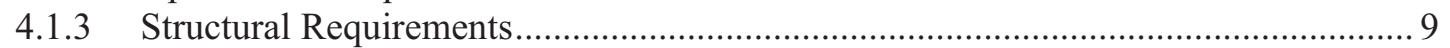

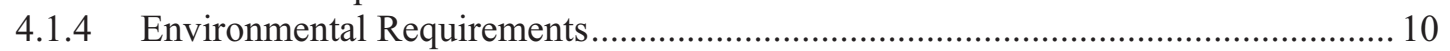

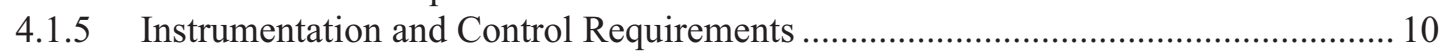

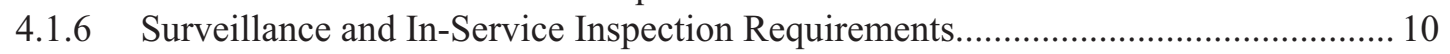

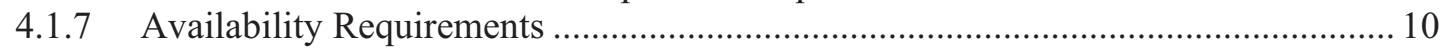

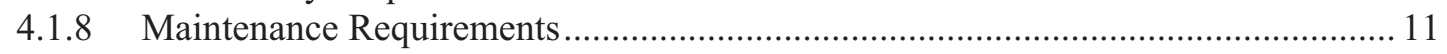

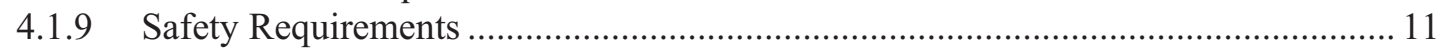

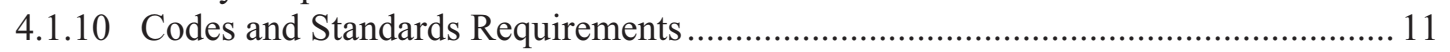

4.1.11 Physical Protection, Material Control and Safeguards - IAEA ................................. 11

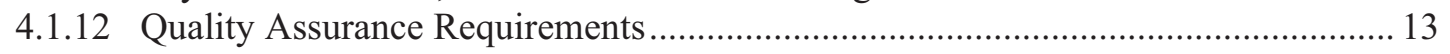

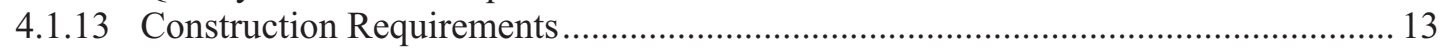

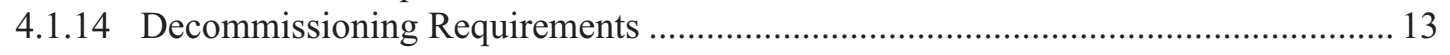

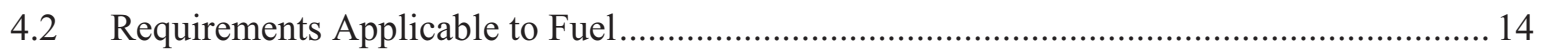

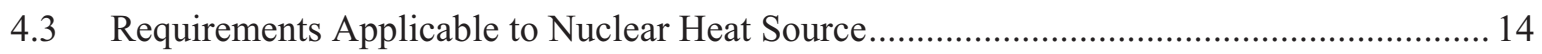

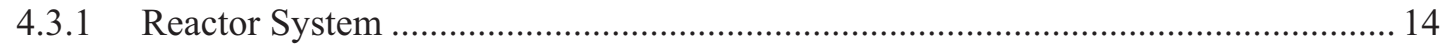

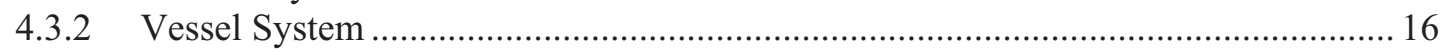

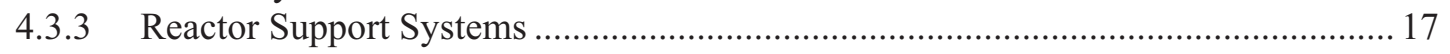

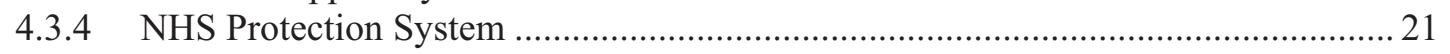

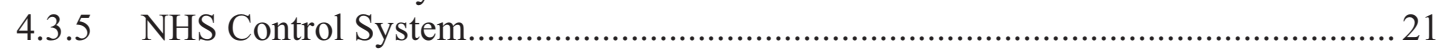

4.3.6 NHS Control Room and Operator Interface System ............................................. 21 


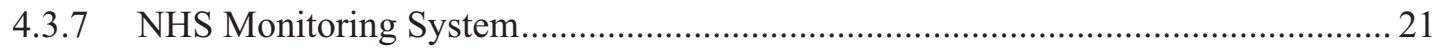

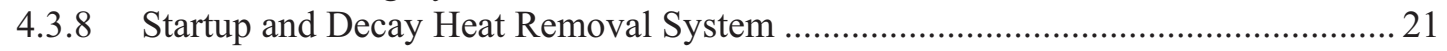

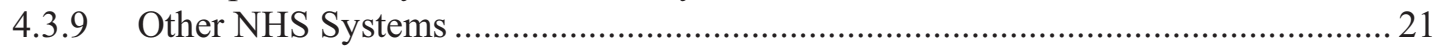

4.4 Requirements Applicable to Heat Transport System ....................................................... 22

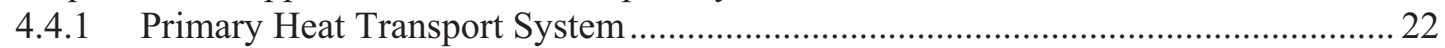

4.4.2 Secondary Heat Transport System (where applied) ............................................... 23

4.5 Requirements Applicable to Power Conversion System..................................................... 23

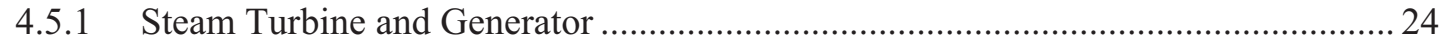

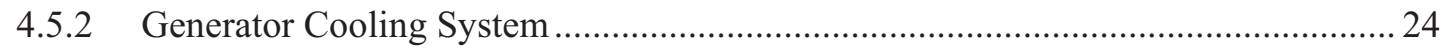

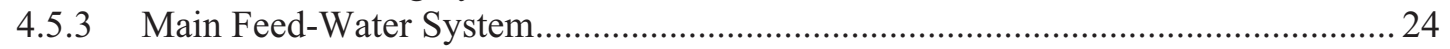

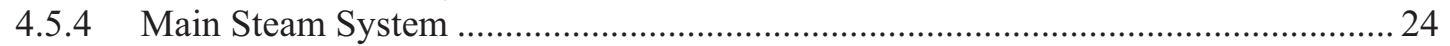

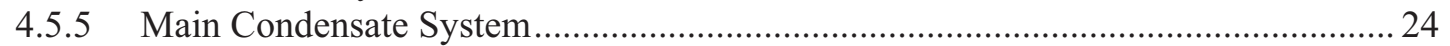

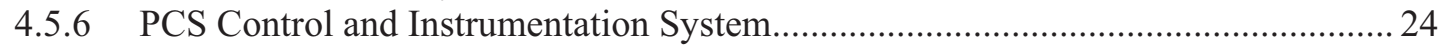

4.6 Requirements Applicable to Hydrogen Production Plant (if and when coupled with

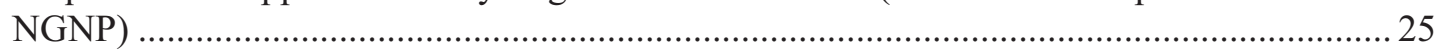

4.6.1 Hydrogen Production Plant Parameters and Performance ..................................... 25

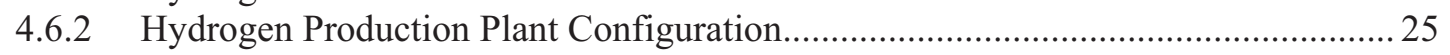

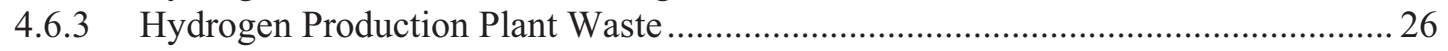

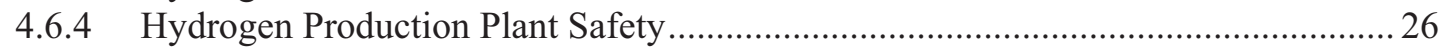

4.6.5 Hydrogen Production Plant Reliability and Availability ........................................ 26

4.6.6 Hydrogen Production Plant Maintenance and In-Service Inspection ....................... 27

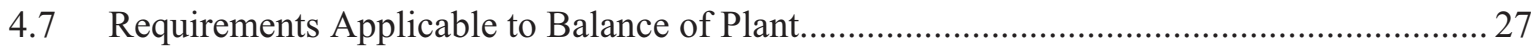

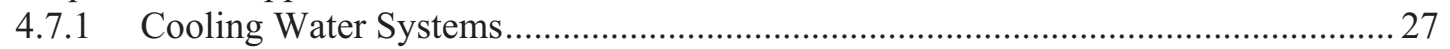

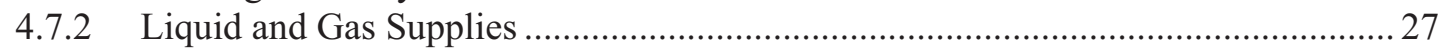

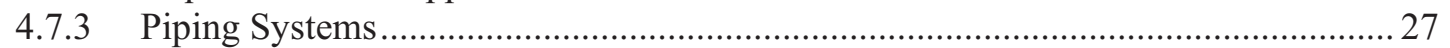

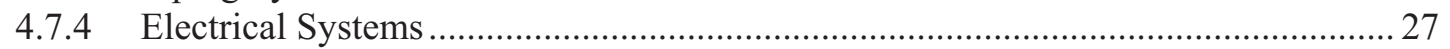

4.7.5 Plant Control Room System.......................................................................... 28

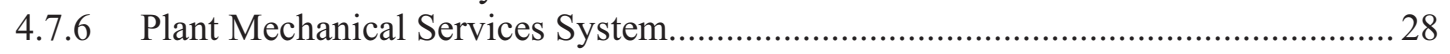

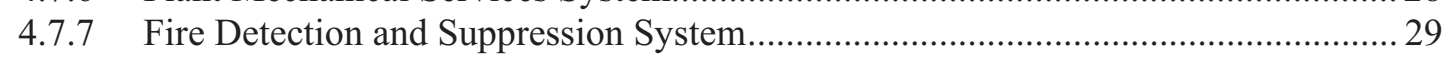

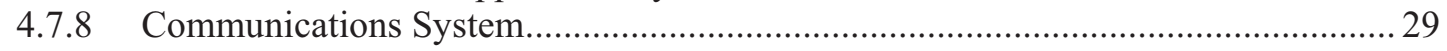

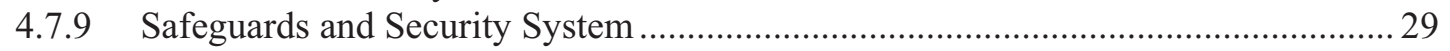

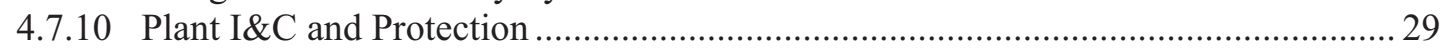

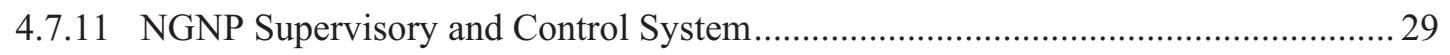

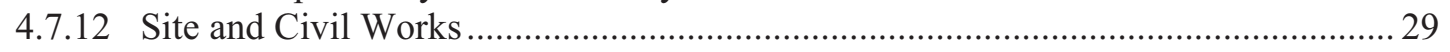

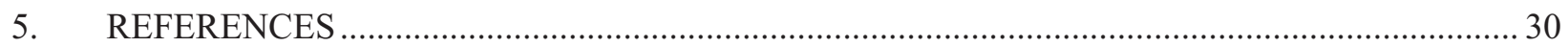




\section{ACRONYMS}

ASME American Society of Mechanical Engineers

B\&PV boiler and pressure vessel

CFR Code of Federal Regulations

DBA design basis accident

DOE U.S. Department of Energy

EPA U.S. Environmental Protection Agency

EPAct Energy Policy Act

F\&OR Functional and Operational Requirements

FERC Federal Energy Regulatory Commission

FHS Fuel Handling System

FOAK first of a kind

GT-MHR Gas Turbine-Modular Helium Reactor

HDA Hot Duct Assembly

HPB Helium Pressure Boundary

HTGR High Temperature Gas-cooled Reactor

HTS Heat Transport System

I\&C Instrumentation and Control

IAEA International Atomic Energy Agency

IHX intermediate heat exchanger

INL Idaho National Laboratory

ISI In-Service Inspection

LEU low-enriched uranium

MHC Main Helium Circulator

MHTGR Modular High Temperature Gas Reactor

NGNP Next Generation Nuclear Plant

NHS Nuclear Heat Source

NOAK "Nth" of a kind

NQA Nuclear Quality Assurance

NRC Nuclear Regulatory Commission

PASSC Plant, Area, Systems, Subsystem (or Structures), and/or Components

PCS Power Conversion System

PGA peak ground acceleration

PHTS Primary Heat Transport System 
RCCS Reactor Cavity Cooling System

SAG Senior Advisory Group

SCS Shutdown Cooling System

SG steam generator

SRM System Requirements Manual

SSE safe shutdown earthquake

TRISO tri-isotropic coated fuel particle design with three materials in coating system (low-density $\mathrm{PyC}$, high-density PyC, and SiC)

UPS uninterruptible power supply 


\section{Next Generation Nuclear Plant System Requirements Manual}

\section{INTRODUCTION AND SCOPE}

\subsection{Introduction}

The Energy Policy Act of 2005, ${ }^{1}$ which was signed into law by President George W. Bush in August 2005, required the Secretary of the U.S. Department of Energy (DOE) to establish a project to be known as the Next Generation Nuclear Plant (NGNP) Project. According to the EPAct, the NGNP Project will consist of the research, development, design, construction, and operation of a prototype plant (to be referred to herein as the NGNP) that (1) includes a nuclear reactor based on the research and development activities supported by the Generation IV Nuclear Energy Systems initiative and (2) shall be used to generate electricity, to produce hydrogen, or to both generate electricity and produce hydrogen. The NGNP Project supports both the national need to develop safe, clean, economical nuclear energy and the Nuclear Hydrogen Initiative, which has the goal of establishing greenhouse-gas-free technologies for the production of hydrogen. DOE has selected the helium-cooled high temperature gas-cooled reactor (HTGR) as the reactor concept to be used for the NGNP because it is the only near-term Generation IV concept that has the capability to provide process heat at high-enough temperatures for the highly efficient production of hydrogen. The EPAct also names Idaho National Laboratory (INL), the DOE's lead national laboratory for nuclear energy research, as the site for the prototype NGNP.

\subsection{Scope of the SRM}

This NGNP System Requirements Manual (SRM) defines the requirements hierarchy for the NGNP with hydrogen production and electricity production and includes initial requirements based on the current maturity state of the NGNP Project.

This document was prepared at the early stages of conceptual design and is to be used as a means to identify and document top-level requirements that apply to various aspects of the NGNP. The requirements hierarchy is structured in a way that allows for further enhancement and the derivation of additional requirements without changing the original structure as the project is further defined. The management of these and future requirements throughout the project life cycle will be the subject of a separate document, "The NGNP Requirements Implementation \& Management Plan," scheduled for completion in FY 2009. This SRM is intended to lead to the development of documents that make up the NGNP Requirements Implementation \& Management Plan.

The requirements in this SRM revision represent only those requirements identified at the current state of plant design, such as those initially identified in the NGNP Pre-Conceptual Design Report and additional requirements or modifications identified via early conceptual design work. With that in mind, and as the requirements identification and documentation process evolves, the scope of these requirements may change. 


\section{REQUIREMENTS HIERARCHY}

\subsection{Overall Requirements Hierarchy}

As noted, the NGNP Requirements Implementation \& Management Plan is in development and scheduled for issue in FY 2009. Figure 1 illustrates the hierarchy of current requirements documents that will comprise the NGNP Requirements Implementation \& Management Plan for the NGNP Project.

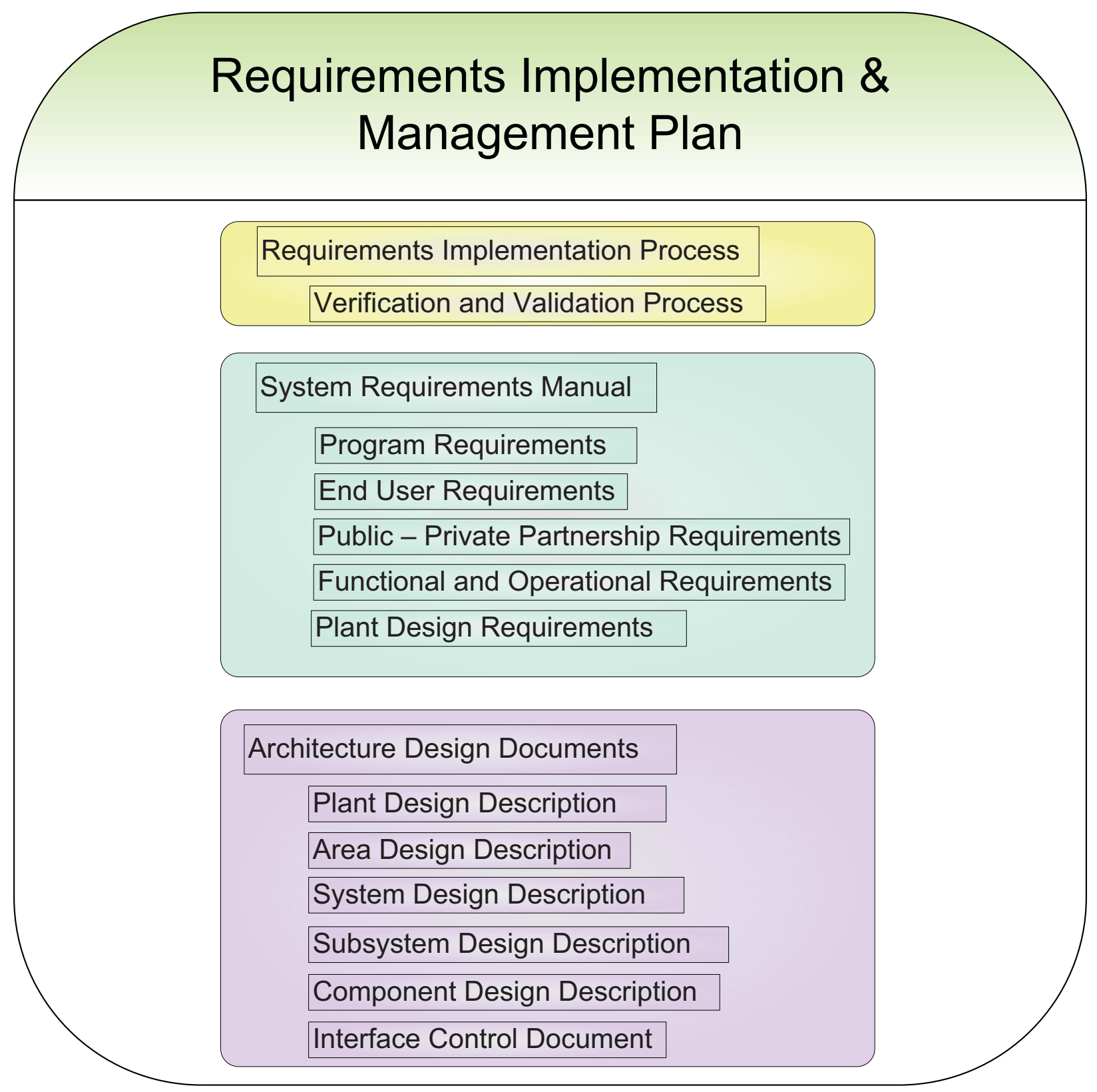

Figure 1. Requirements Implementation \& Management Plan document hierarchy.

At the top level, requirements are derived from Program Requirements (e.g., 2005 EPAct, DOE Request for Information/Expression of Interest, regulatory requirements), End-User Requirements, and the Public/Private Partnership. From these top-level requirements (customer input), functions are 
analyzed and Functional and Operational Requirements (F\&OR) are developed to cover, for example, availability, reliability, maintainability, transportability, manufacturability, and operability. Ultimately, technical requirements, including design requirements and design criteria, are developed for all plant areas, systems, subsystems (or structures), and/or components (PASSC). These requirements then form the bases for developing specifications, drawings, system descriptions, etc., required for the final design, construction, testing, and commissioning of the plant.

A traditional Verification and Validation process will be applied. Verification confirms that the PASSC has been constructed (implemented) and performs as required to meet its intended form, fit, and function (e.g., through successful completion of inspections, tests, evaluations), and that necessary and sufficient operational, maintenance, and surveillance (or in-service) test and inspection processes are in place to ensure continued reliable performance of the PASSC throughout plant life. Validation confirms that the PASSC design basis documentation and analyses (e.g., calculation inputs, assumptions and design criteria, specifications, drawings) are consistent with the technical, functional, licensing, and operational requirements of the PASSC.

Within this hierarchy, the requirements are based on the physical structure of the plant where the plant is divided into NGNP PASSCs. The lowest levels of requirements are at the plant design level. Detailed requirements are documented in the Plant Design Requirements for all PASSCs within the five areas of NGNP

1. Nuclear Heat Source (NHS)

2. Heat Transport System (HTS)

3. Power Conversion System (PCS)

4. Hydrogen Production System

5. Balance of Plant.

\subsection{Conceptual Design Requirements Process}

The requirements summarized in this revision of the SRM were originally developed by the reactor Suppliers during the pre-conceptual design phase of the NGNP Project. The top-level requirements were derived from NGNP Project goals and objectives as well as applicable regulatory requirements. At the system and subsystem level, some of the requirements were developed by the reactor Suppliers from prior gas reactor designs, such as the AREVA ANTARES design, the General Atomics Gas Turbine-Modular Helium Reactor (GT-MHR) and Modular High Temperature Gas Reactor (MHTGR) designs, and the Pebble Bed Modular Reactor Demonstration Pilot Plant design. The set of requirements summarized herein are judged sufficient for the early NGNP conceptual design work and set the starting point for the subsequent stages of design. 


\section{NGNP TOP-LEVEL REQUIREMENTS \\ 3.1 NGNP Mission Need}

The NGNP Project mission is the development of a full-scale commercial plant demonstration that provides (a) high-efficiency electricity generation and (b) $\mathrm{CO}_{2}$-free hydrogen production based on high temperature, modular gas-cooled, graphite moderated reactor technology as the heat source. The mission need statement developed for NGNP was approved by the DOE Deputy Secretary on October 18, 2004, officially completing CD-0. High-level NGNP Project objectives that support the mission need are, as identified in Reference 2:

1. Develop and implement the technologies important to achieving the functional performance and design requirements determined through close collaboration with commercial industry end-users.

2. Demonstrate the basis for commercialization of the nuclear system, a heat transfer/transport system, a hydrogen production process, and a power conversion concept. An essential part of the hydrogen operations will be demonstrating that the requisite reliability and capacity factor can be achieved over an extended period of operation.

3. Establish the basis for licensing the commercial version of the NGNP by the Nuclear Regulatory Commission (NRC). This will be achieved in major part through licensing of the prototype by the $\mathrm{NRC}$ and initiating the process for certification of the nuclear system design.

4. Foster rebuilding of the U.S. nuclear industrial infrastructure and contributing to making the U.S. industry self-sufficient for our nuclear energy production needs.

\subsection{NGNP Project Requirements}

The following provides an overview of the various project requirements that have been identified and/or used to date. Once DOE's Financial Offer of Assistance and Design Approach is finalized, this SRM will be revised to be consistent with this strategy and approach.

\subsubsection{NGNP Project Requirements at Pre-Conceptual Design}

The following requirements were adapted from Reference 3 as modified by the Independent Technology Review Group recommendations and documented in Reference 4. These served as the NGNP Project requirements at the time of Pre-Conceptual Design.

1. NGNP shall be designed, constructed, licensed, and operating by 2021.

2. NGNP design configuration shall consider cost and risk profiles to ensure that NGNP establishes a sound foundation for future commercial deployment.

3. NGNP nuclear heat source shall be based on the HTGR concept and utilize passive safety features to cool the core from full power to safe shutdown conditions.

4. NGNP shall produce high-efficiency electricity and generate hydrogen on a scale that sets a foundation for future commercial deployment.

5. NGNP shall be licensed by the NRC as a commercial cogeneration facility producing electricity and hydrogen.

6. NGNP shall include provisions for future testing.

7. NGNP shall enable demonstration of energy products and processes utilizing its nuclear heat source. 
8. The Project shall include identification of necessary and sufficient research and development technical scope and priorities.

9. NGNP licensing shall support potential future NRC technology neutral rule-making activities (i.e., Risk-Informed, Performance-Based Alternative to 10 CFR Part 50).

\subsubsection{HTGR Fundamental Requirements}

A Senior Advisory Group (SAG) comprised of senior personnel from the HTGR suppliers, owneroperators, and potential end-users was formed to advise the NGNP Project on commercial interests in application of the HTGR technology. In September and October 2008, the SAG was convened to provide its perspective on the priorities for the 2009 NGNP Project work scope. The SAG also identified the range of potential applications that would most likely be acceptable to the commercial sector for a first-of-akind (FOAK) plant demonstrating the capabilities of the HTGR technology. The SAG considers that these include providing electricity and steam in a co-generation application and/or in recovery of oil sands or shale. The HTGR Suppliers then provided recommended reference plant configurations considered best suited to these applications. Reflecting the products offered by the Suppliers, two configurations were proposed; one based on the pebble bed reactor design, the other based on the prismatic reactor design.

The pebble bed reference design configuration includes an Intermediate Heat Exchanger (IHX) in the primary loop with a secondary gas loop that transports energy to the energy conversion processes (e.g., steam generator supplying a steam turbine electricity generator and process steam demands). The prismatic reference design configuration includes a steam generator in the primary loop with a secondary steam loop supplying the energy conversion processes, (e.g., steam turbine generator and process steam demands). Using the list of potential applications and the reference configurations as the basis, the SAG developed a list of HTGR fundamental requirements for the NGNP as a first-of-a-kind plant. The deliberations and detailed list of these requirements are documented in Reference 11.

This list is based on the SAG's collective view of the fundamental requirements that the NGNP must meet in order to support development of a viable commercial HTGR offering. This list of requirements is not fully consistent with the requirements of the EPAct that informed the NGNP pre-conceptual design. Specifically, the SAG recommendations do not include a hydrogen process in the FOAK Plant, the plant could be sited at a commercial facility or at INL and the reactor outlet temperature will be lower than that assumed in the PCDR $\left(750^{\circ} \mathrm{C}\right.$ to $800^{\circ} \mathrm{C}$ instead of $900^{\circ} \mathrm{C}$ to $\left.950^{\circ} \mathrm{C}\right)$. These views will be fully developed and expressed in the industry's responses to the pending issue of an Offer of Financial Assistance from the DOE and the initiation of a public-private partnership for completion of the NGNP Project. In anticipation that these views will persist and inform the direction of the public-private partnership, the NGNP Project is adopting the requirements recommended by the SAG for ongoing conceptual design work. They are included as appropriate throughout this SRM, particularly in Section 4. For completeness, the following summarizes these requirements:

1. The Nuclear Heat Supply System shall be design certified for a broad range of applications and sites. Note that the Nuclear Heat Supply System includes the nuclear island (e.g., the reactor, primary coolant system, and supporting systems) and the heat transfer/transport system.

2. The NHSS shall be licensed independent of the application. In this regard the licensing boundary and interface requirements shall be defined for the reference configurations (e.g., transients, feed and gas return chemistry.

3. Applicable to broad range of cogeneration applications supplying, singly or in combination, electricity, steam, and hot gas.

4. Reactor gas outlet temperature in the range of 750 to $800^{\circ} \mathrm{C}$. 
5. Capable of completing design, licensing, construction, and startup testing for initial operation by 2021.

6. Capable of controlling the transport of radionuclides to the end products at levels below the concentration or exposure requirements for the product (e.g., tritium in steam, gas, hydrogen). (Initial acceptable tritium levels will be set at a fraction of the U.S. Environmental Protection Agency [EPA] limits for drinking water and air.)

7. Can be collocated with the process; Protective Action Guidelines limits at site boundary of approximately 400 meters.

8. Capable of following process load variations.

9. Costs for anticipated "Nth"-of-a-kind (NOAK), based on design certification, construction, and operation of first-of-a-kind (FOAK) design, supports viable economic business model (competitive with natural gas price at $\$ 8 / \mathrm{MMBtu}$ )

10. Normal maintenance exposure target limit of no more than 50 person-REM/year per module in a refueling year.

11. Target availability factor of greater than or equal to $90 \%$.

12. Target plant design lifetime of 60 years (calendar).

\subsection{Regulatory Documents}

The following regulatory documents from various regulatory bodies are applicable to the NGNP.

\subsubsection{NRC/EPA Regulatory Documents}

Federal regulatory requirements are defined by the Code of Federal Regulations (CFR), which is controlled by several regulatory bodies, such as the NRC and the EPA. Specific documents include, as a minimum:

1. 51 CFR 28044, Policy Statement on Safety Goals for the Operation of Nuclear Power Plants

2. 10 CFR 20, Standards for Protection Against Radiation, (Permissible dose levels and activity concentrations in restricted and unrestricted areas).

3. 10 CFR 50, Domestic Licensing of Production and Utilization Facilities (applicable portions as needed)

4. 10 CFR 51, Environmental Protection Regulation for Domestic Licensing and Related Regulatory Functions

5. 10 CFR 52, Licenses, Certifications, and Approvals for Nuclear Power Plants

6. 10 CFR 50, Appendix I - Numerical Guides for Design Objectives and Limiting Conditions for Operation to Meet the Criterion "as Low as is Reasonably Achievable" for Radioactive Material...

7. 10 CFR 73, Physical Protection of Plants and Materials

8. 10 CFR 74, Material Control and Accounting of Special Nuclear Material

9. 10 CFR 75, Safeguards on Nuclear Material - Implementation of US/IAEA (International Atomic Energy Agency) Agreement

10. 10 CFR 95, Facility Security Clearance and Safeguarding of National Security Information and Restricted Data 
11. 10 CFR 100, Reactor Site Criteria, (Numerical dose guidelines for determining the exclusion area boundary, low population zone, and population center distances)

12. 10 CFR 835, Occupational Radiation Protection

13. 29 CFR 1910, Occupational Safety and Health Standards, Subpart H, Hazardous Materials

14. 40 CFR 50-99, Clean Air Act

15. 40 CFR 100-149, Clean Water Act

16. 40 CFR 190, Environmental Radiation Protection Standards for Nuclear Power Operations

17. 40 CFR 1502, Environmental Impact Statement

18. EPA, 520/1-75-001, Protective Action Guide Doses for Protective Actions for Nuclear Incidents

19. Nuclear Regulatory Commission, NUREG-1860, Vols. 1 and 2, Feasibility Study for a Risk-Informed and Performance-Based Regulatory Structure for Future Plant Licensing, December 2007. (NGNP plant licensing shall be consistent with the NRC new regulatory framework developed as a guide for future plant licensing for advanced [non-light water] reactors).

20. Nuclear Regulatory Commission, 10 CFR Part 50 [NRC-2008-0237], Policy Statement on the Regulation of Advanced Reactors, Final policy statement (FR Doc E8-24268), effective November 13, 2008.

21. Nuclear Regulatory Commission, Regulatory Guide 1.206, Combined License Applications for Nuclear Power Plants (LWR Edition), June 2007

22. Nuclear Regulatory Commission, NUREG-0800, Standard Review Plan for the Review of Safety Analysis Reports for Nuclear Power Plants, March 2007

\subsubsection{DOE Documents}

The acquisition strategy for the NGNP Project may include a combination of requirements from both the federal and commercial sectors. Until a better definition of the commercial participant(s) is obtained, the DOE Acquisition Management system will be used as a guide in establishing the appropriate work scope, including the documents listed below (see Reference 5).

1. DOE O 413.3A, Program and Project Management for the Acquisition of Capital Assets

2. DOE O 420.1B, Facility Safety

3. DOE O 435.1, Radioactive Waste Management

4. DOE Policy 450.4, Safety Management System Policy

5. DOE O 450.1A, Environmental Protection Program

6. 10 CFR 851, Worker Safety and Health Program

7. DOE M 470.4-2 Chg.1, Physical Protection.

\subsubsection{FERC Regulations}

The Federal Energy Regulatory Commission (FERC) sets requirements for all electricity being fed into the national power grid. Because the NGNP is expected to produce electricity for commercial use, it must follow applicable FERC requirements. See www.ferc.gov for information. 


\subsubsection{State of Idaho Regulations}

Should the NGNP be sited at the INL, as indicated in the 2005 EPAct, the NGNP must meet applicable state requirements and observe treaties with sovereign nations such as the Shoshone -Bannock.

\subsubsection{Indian Reservation Rights}

The Shoshone-Bannock Tribes are the region's primary Native American residents. Because they believe the land is sacred, the entire INL reserve is potentially culturally important to them. They consider cultural resources to the Shoshone-Bannock peoples include all forms of traditional life ways and usage of all natural resources. This includes not only prehistoric archaeological sites, which are important in religious or cultural heritage context, but also features of the natural landscape, air, plant, water, or animal resources that might have special significance. DOE has committed to additional interaction and exchange of information with the Shoshone-Bannock Tribes at the Fort Hall Reservation.

\section{FUNCTIONAL, OPERATIONAL, AND TECHNICAL REQUIREMENTS}

The subsections below summarize the NGNP F\&ORs and Technical Requirements, as well as Plant Design Requirements, as defined at the beginning of the Conceptual Design phase. These are based on the FY 2007 pre-conceptual design work for NGNP, as partially updated by SAG involvement (see Section 3.2.3) and early conceptual design work (see Reference 5). These requirements will be updated as the project matures, particularly after the nuclear system design, plant operating conditions, and plant configuration are finalized. At that time, a formal numbering system will be instituted that will be consistent with the final configuration of the plant. For this revision of the SRM, the requirements listed in Section 4.1 and Section 3.2.3 constitute the high-level F\&ORs and technical requirements set as currently identified. Those requirements listed in the remainder of Section 4 are provided at this time as guidance only for the development of reference configuration specific SRMs by the Suppliers.

\subsection{Requirements Applicable to Multiple Systems, Buildings and Structures}

\subsubsection{System Configuration and Essential Features Requirements}

System configuration and essential features requirements are as follows:

1. The NGNP nuclear heat source (NHS) shall use the HTGR concept.

2. The NGNP NHS shall demonstrate commercial viability of the HTGR.

3. The NGNP NHS shall be designed such that it can be design certified for a broad range of applications and sites.

4. The NGNP design will be applicable to a broad range of cogeneration applications supplying, singly or in combination, electricity, steam, and hot gas.

5. The NGNP design will be such that the HTGR can be collocated with the process; PAG limits met at the site boundary of approximately 400 meters.

6. The costs for the anticipated NOAK, based on design certification, construction, and operation of FOAK design, shall support a viable economic business model (i.e., competitive with natural gas at the on-going price). 
7. For the NGNP (FOAK), the designed reactor gas outlet temperature shall be in the range of 750 to $800^{\circ} \mathrm{C}$.

\subsubsection{Operational Requirements}

Operational requirements are as follows:

1. The NGNP NHS shall have an operational lifetime of 60 years (calendar).

2. The NGNP plant shall be capable of following process load variations.

3. The NGNP shall be designed to use low-enriched uranium (LEU) TRISO-coated particle fuel.

4. The NGNP shall demonstrate a minimum 18-month refueling interval capability (if applicable).

5. The NGNP shall be designed to operate during loss of secondary heat process, such as hydrogen production, and stabilize in the electricity generation phase.

6. The NGNP shall be designed so as to support the anticipated NOAK design to have a normal maintenance exposure target limit of no more than 50 person-REM/year per module in a refueling year.

\subsubsection{Structural Requirements}

Structural requirements are as follows:

1. NGNP PASSCs shall be designed and constructed using and demonstrating modular plant construction.

2. The NGNP shall be designed for a reference safe shutdown earthquake (SSE) horizontal peak ground acceleration (PGA) of $[0.3 \mathrm{~g}]$. $^{\mathrm{a}}$

3. The NGNP shall be designed such that the minimum level at which a shutdown is required to evaluate the condition of the plant following an earthquake shall be [0.1g] PGA.

4. A seismic margin assessment shall be performed to demonstrate that there is seismic margin in the NGNP beyond the design level SSE. The seismic margin earthquake used in the seismic margin assessment process shall be the NUREG/CR-0098 median shape curve anchored to a [0.5g] PGA.

5. NGNP plant external structures, important to safety, shall be designed and constructed with consideration of aircraft impacts, as required by NRC final rule RIN 3150-AI19.

a. Items appearing in brackets ([ ] ) represent approximations and/or undefined values. 


\subsubsection{Environmental Requirements}

Environmental requirements are as follows:

1. The NGNP and hydrogen production facilities (if applicable) shall comply with applicable requirements of the Clean Air Act/Air Programs.

2. The NGNP shall identify all waste treams generated in NGNP by type and estimated quantity, providing a disposition pathway within the applicable regulatory framework.

3. The NGNP Project shall minimize the generation of all waste, including radioactive, nonradioactive, and mixed waste, and it shall comply with applicable DOE orders, NRC regulations, and EPA regulations in the treatment of these wastes.

4. The design of the NGNP shall incorporate features consistent with decommissioning and decontamination best practices.

5. The NGNP and NOAK plant will be capable of controlling the transport of radionuclides to the end products at levels below the concentration of exposure requirements for the product (e.g., tritium in steam, gas hydrogen). (Initial acceptable tritium levels will be set at a fraction of the EPA limits for drinking water and air)

\subsubsection{Instrumentation and Control Requirements}

Instrumentation and control (I\&C) requirements are as follows:

1. The NGNP shall be capable of being controlled from a single control room.

2. The main control room shall include controls for the PCS and high-temperature heat transport loop.

3. The NGNP design shall optimize the human-machine interface based on human factors engineering principles and operating experience to the extent possible without compromising plant safety.

\subsubsection{Surveillance and In-Service Inspection Requirements}

Surveillance and In-Service Inspection (ISI) requirements are as follows:

1. The NGNP design shall provide access to the primary and secondary, if applicable, loop pressure boundary to permit ISI as required by appropriate sections of the American Society of Mechanical Engineers (ASME) Boiler and Pressure Vessel (B\&PV) Code, minimizing the need for requests for Code relief due to accessibility constraints.

\subsubsection{Availability Requirements}

The SAG has established a target availability factor of greater than or equal to $90 \%$. Specific availability requirements will be determined by the end-user and will include the following:

1. Excluding NGNP mission-specific outages for inspection and testing, the NGNP design capacity factor for supplying process heat over the plant lifetime shall be at least [TBD \%] when modeled with equipment mean time to failure and mean time to repair data for the same or similar systems and components.

2. Excluding NGNP mission-specific outages for inspection and testing, the capacity factor loss due to NGNP planned outages averaged over the lifetime of the plant shall not exceed [TBD \%], including all planned inspection and maintenance activities that must be accomplished with the reactor shut down. 
3. Excluding NGNP mission-specific outages for inspection and testing, the calculated capacity factor loss due to unplanned outages averaged over the lifetime of the plant shall not exceed [TBD \%].

\subsubsection{Maintenance Requirements}

Maintenance requirements are as follows:

1. The NGNP design shall include provisions for monitoring equipment status, configuration, and performance and for detecting and diagnosing malfunctions as a basis for predictive maintenance plans and decision making.

\subsubsection{Safety Requirements}

Safety requirements are as follows:

1. The nuclear system safety basis shall not depend on active cooling systems during design basis accident (DBA) conditions.

2. Protection Criteria for the Worker and the Public are as follows:

a. Upper bound offsite doses during design basis events shall meet 10 CFR 50.34 with margin.

b. There shall be a technical basis for eliminating or minimizing the need for offsite emergency planning. This technical basis shall consider a risk-informed, realistic assessment of design basis and beyond design basis accidents and shall demonstrate high confidence that the EPA Protection Action Guidelines are met. The NGNP design shall effectively demonstrate that emergency plan requirements may be minimized (e.g., eliminate requirements for emergency drills, sirens, etc.).

c. Exposure to the Worker and the Public under normal operation shall meet 10 CFR 20 and ALARA (as low as reasonably achievable) as quantified in Appendix I of 10 CFR 50.

\subsubsection{Codes and Standards Requirements}

Codes and standards requirements are as follows:

1. The design of the NGNP shall comply with all applicable federal, state, and local codes and standards. Codes and standards pertinent to the nuclear industry shall only be used in the design, fabrication, and installation of the structures, systems, and equipment where such codes and standards are applicable. The plant designer shall list all applicable codes and standards, and the applicable revision of each document.

2. NUREG/CR-5973 shall be used as a starting point for the identification of codes and standards to be followed during conceptual design.

3. Because the NGNP will be built within a DOE facility and will interface with other existing facilities, the plant designer must evaluate DOE orders to ensure that the NGNP can interface with the DOE site and be acceptable to DOE.

\subsubsection{Physical Protection, Material Control and Safeguards - IAEA}

These requirements are presented in the context of physical protection against theft, sabotage, and other terrorist activities; protection, control, and accountability of nuclear materials; and international safeguards. These are covered principally under 10 CFR 73, 10 CFR 74, and 10 CFR 75, although some DOE directives (especially DOE G 413.3-3 and the DOE 470 P, O, and M series) are also relevant. NRC, DOE (including National Nuclear Security Administration), and IAEA policies and regulations are evolving significantly affecting design policy now and likely continuing into the future. Further issues 
include methodologies to provide concurrent consideration of safety and security (including safeguards) through their integration into the design process. In opening the policy, NRC states that international safeguards shall be considered during the design.

As compared to current generation light-water reactors, NRC expects that advanced reactors will provide enhanced margins of safety and use simplified, inherent, passive, or other innovative means to accomplish their safety and security functions. In the policy statement on the regulation of advanced reactors, ${ }^{6}$ the NRC identified various desirable attributes to be considered during the design process including:

1. "Designs that include considerations for safety and security requirements together in the design process such that security issues (e.g., newly identified threats of terrorist attacks) can be effectively resolved through facility design and engineered security features, and formulation of mitigation measures, with reduced reliance on human actions."

2. "Designs with features to eliminate or reduce the potential theft of nuclear materials."

3. "Designs that emphasize passive barriers to potential theft of nuclear materials."

In concluding the policy, "Finally, the NRC also believes that it will be in the interest of the public as well as the design Suppliers and the prospective license applicants to address security issues early in the design stage to achieve a more robust and effective security posture for future nuclear power reactors."

\subsubsection{Physical Protection of Plants and Materials}

1. The design of the NGNP shall comply with 10 CFR 73, Physical Protection of Plants and Materials.

2. The design of NGNP shall possess features to eliminate or reduce the potential theft of nuclear materials.

3. The design of NGNP shall emphasize passive barriers to potential theft of nuclear materials.

4. The design of the NGNP shall incorporate design features intended to provide physical protection against acts of sabotage that could create a radiological hazard to the personnel or a potential radioactive release to the public and the environment.

5. The design of the NGNP shall comply with 10 CFR 73.55, Requirements for physical protection of licensed activities in nuclear power reactors against radiological sabotage.

6. The design of the NGNP shall comply with 10 CFR 73.67, Licensee fixed site and in-transit requirements for the physical protection of special nuclear material of moderate and low strategic significance.

7. Measures that have been designed into the NGNP for safety purposes shall be taken into account, to the extent practicable; these safety features should be designed and located within the NGNP in a manner that facilitates sabotage and theft protection, including consideration of damage control/recovery actions from sabotage attempts.

8. There shall be concurrent consideration of safety and security, which will commence at the beginning of the design process.

9. The design of the NGNP shall include preparation and update of a Security Assessment, "High Assurance Evaluation and Mitigative Measures Evaluation" per NUREG-800 Sections 13.6.4 and 13.6.5, and the development of Physical Security Hardware Inspections, Tests, Analyses, and Acceptance Criteria (ITAAC) per NUREG-0800 Section 14.3.12. The results of and insight from these evaluations and the ITAAC shall be used to integrate safeguards by design into the NGNP. 


\subsubsection{Material Control and Accounting of Special Nuclear Material}

1. The design of the NGNP shall comply with 10 CFR 74, Material Control and Accounting of Special Nuclear Material

2. The NGNP shall incorporate design features facilitating implementation of material control and accounting procedures that are sufficient to enable the NGNP operating organization to account for the special nuclear material in its possession.

3. The NGNP design shall comply with NRC requirements for the control and accounting of special nuclear material including 10 CFR 74.19, Recordkeeping.

\subsubsection{Safeguards on Nuclear Material - Implementation of US/IAEA Agreement}

1. The design of the NGNP shall comply with 10 CFR 75, Safeguards on Nuclear MaterialImplementation of US/IAEA Agreement

2. The design of the NGNP shall incorporate design features to facilitate the application of international safeguards under INFCIRC/57, The Text of the Agreement for the Application of Agency Safeguards to United States Reactor Facilities, and INFCIRC/540, Model Protocol Additional to the Agreements(s) Between State(s) and the International Atomic Energy Agency for the Application of Safeguards.

\subsubsection{Quality Assurance Requirements}

The Quality Assurance requirement is as follows:

1. The NGNP Project shall use the U.S. national consensus standard ASME Nuclear Quality Assurance (NQA)-1-2000, "Quality Assurance Program Requirements for Nuclear Facilities Applications.",

\subsubsection{Construction Requirements}

Construction requirements are as follows:

1. Advanced techniques, such as the use of factory or field-fabricated and assembled modules containing portions of systems and/or structures, shall be used (as appropriate) to reduce erection costs and schedule risks and to enhance quality control.

2. The design of buildings and equipment shall facilitate plant construction and the installation, repair, and replacement of equipment.

\subsubsection{Decommissioning Requirements}

The decommissioning requirement is as follows:

1. Upon completion of its useful life, the NGNP nuclear heat source shall be put into a condition of safe storage for 10 years and then decommissioned and dismantled to allow continued use of the land as a power plant or industrial site.

b. The NGNP Project is currently evaluating implementation of NQA-1-2008, pending NRC acceptance. 


\subsection{Requirements Applicable to Fuel}

The fuel performance shall allow for a source term calculation capable of obtaining an NRC license with an exclusion zone of no more than 400 meters (approximately) for the design power level.

The fuel shall be designed with the following requirements:

As-manufactured Quality Requirements, at a 95\% confidence level:

1. Heavy metal contamination: $\leq 2 \times 10^{-5}$ (Prismatic Block); $\leq 6.0 \times 10^{-5}$ (Pebble Bed)

2. SiC Defect Fraction: $\leq 1 \times 10^{-4}$ (Prismatic Block); $\leq 6.0 \times 10^{-5}$ (Pebble Bed)

In-service Fuel Performances Requirements, at a 95\% confidence level:

1. Fuel failure during normal operations: $\leq 2 \times 10^{-4}$ (Prismatic Block); $\leq 4.6 \times 10^{-5}$ (Pebble Bed)

2. Incremental fuel failures during accident conditions: $\leq 6.0 \times 10^{-4}$ (Prismatic Block); $\leq 5.0 \times 10^{-4}$ (Pebble Bed)

\subsection{Requirements Applicable to Nuclear Heat Source}

\subsubsection{Reactor System}

The following are the required functions of the reactor system:

1. Generate and control the generation of heat and transfer it to the primary coolant

2. Have the capability to maintain reactor shutdown as required under normal operating, abnormal operating, and accident conditions.

3. Control chemical attack of the fuel and graphite components within the core

4. Maintain primary pressure boundary integrity and containment of primary fluids and radionuclides. The reactor system shall be designed with the following requirements:

1. The reactor system shall be designed to provide passive residual heat removal under conditions of loss of forced cooling and loss of coolant.

2. The reactor system shall be designed such that the reactor core is maintained in a coolable geometry under all normal operating, abnormal operating, and postulated design basis and beyond design basis accident conditions.

3. The reactor system shall be designed for an operational lifetime of 60 years (calendar). Excluding those portions of the system that can be replaced.

4. The core shall use forced circulation helium as the heat transport fluid.

5. Non-replaceable structural materials in contact with helium shall resist corrosion and erosion during plant life as to avoid failure and or need for replacement.

\subsubsection{Reactor Core}

The following are the required functions of the reactor core:

1. Generate heat

2. Transfer heat to coolant and/or reactor internals. 
The following requirements shall be placed on the reactor core:

1. The decay heat removal shall be possible by passive heat transfer means (conduction and radiation) from the fuel to the reactor internals without reaching unacceptable fuel temperatures during all DBA conditions.

2. The core shall utilize thermal spectrum neutrons for fission reaction.

3. The core shall be moderated with graphite.

4. The active core height shall ensure the axial stability of the neutron flux and preclude the risk of xenon oscillations.

5. Reference fuel shall be LEU-based $\left(\mathrm{UCO}\right.$ or $\left.\mathrm{UO}_{2}\right)$ with an enrichment limited to $<20.0 \%$ (in mass) and with a peak burnup limited to $20 \%$ fissions per initial metal atom (FIMA).

6. The core bypass flow shall be maintained within an acceptable range [TBD], to ensure fuel temperatures in normal and accidental conditions are maintained within [TBD] limits (existence of a minimum amount of bypass in lateral reflector).

7. The reactivity temperature coefficient shall be sufficiently negative to shut down the nuclear chain reaction before an unacceptable fuel temperature is reached and maintain the core in a safe state for a time offering the certainty to reliably introduce absorber elements.

\subsubsection{Reactor Internals}

The following are the required functions of the reactor internals:

1. Maintain reactor core geometry

2. Provide heat transfer during conduction cool down

3. Conserve neutrons in the reactor core and provide shielding. The following are requirements on the reactor internals:

1. The reactor internals shall be designed to properly control bypass flows.

2. The reactor internals shall be designed to transport residual decay heat from the reactor core to the reactor vessel.

3. The reactor internals shall be designed to channel primary coolant to and from the reactor core for transfer of heat to the Primary Heat Transport System (PHTS).

4. The reactor internals shall be designed to provide radiological shielding to limit neutron fluence to the reactor vessel.

5. The reactor internals shall be designed to limit gamma radiation exposure to the plant personnel and equipment.

6. The reactor internals shall be designed to limit damage to plant components during conduction cooldown events.

\subsubsection{Neutron Control Elements}

The following is the required function of the neutron control elements:

1. Control the nuclear chain reaction in the reactor core by absorbing neutrons in any operational mode. 
The following is the requirement placed on the neutron control elements:

1. The neutron control elements shall be designed to provide sufficient negative reactivity to shut down the reactor and maintain it in subcritical condition for any state by compensating the worst positive reactivity insertion.

\subsubsection{Vessel System}

The following is the required function of the vessel system:

1. Contain and support the components of the reactor core, reactor internal supports and structures, and the nuclear heat transport components.

The vessel system shall be designed with the following requirements:

1. The duration of maintenance, ISI, and repair/replacement operations of the vessel system shall be minimized.

2. All parts of the vessel system shall be designed for an operating duration of 60 years.

3. Lifetime of isolation valves, piping and cross-vessels (where applicable) of the vessel system shall be optimized according to the investment cost and replacement duration.

4. The vessel system shall be designed for design basis duty-cycle events.

\subsubsection{Reactor Vessel}

The following are the required functions of the reactor vessel:

1. Provide core support and maintain its relative position to the control rods

2. Provide decay heat and residual heat removal by radial conduction during conduction cooldown. The following are requirements placed on the reactor vessel:

3. During normal operation, the reactor vessel shall maintain its operating temperature through a thermal balance between the core heat flux, core inlet helium flow, and the reactor cavity cooling system.

4. The reactor vessel shall maintain the primary pressure boundary integrity.

5. The operating conditions shall be considered according to the following statements:

a. In normal operation, the creep effects on the reactor vessel shall be avoided (negligible creep).

b. No leakage shall result from anticipated operating occurrences (AOO).

c. For AOOs and DBAs, the reactor vessel shall not prevent restarting of the plant.

\subsubsection{Cross Vessels (where applied)}

The following is the required function of the cross vessels:

1. Provide a primary heat transport path to/from the reactor vessel and Intermediate heat exchanger (IHX) vessels.

The following are requirements placed on the cross vessels:

1. The cross vessels shall maintain the primary pressure boundary integrity.

2. The cross vessels shall provide the primary heat transport path to/from the reactor vessel and IHX vessels. 


\subsubsection{IHX Vessels (where applied)}

The following is the required function of the IHX vessels:

1. Support the IHX modules.

The following is the requirement of the IHX vessels:

1. The IHX vessels shall maintain the primary pressure boundary integrity.

\subsubsection{Vessel Supports}

The main requirements of the vessel supports are as follows:

1. The vessel supports shall support the vertical load.

2. The vessel supports shall include keying for lateral support.

3. The vessel supports shall accommodate thermal expansion.

4. The vessel supports shall accommodate duty-cycle events.

5. The vessel supports shall withstand coupled vibration from the circulator.

\subsubsection{Pressure Relief System}

The following is the required function of the pressure relief system:

1. Provide the primary coolant loop's overpressure protection as required by ASME pressure relief code. The following requirement is placed on the pressure relief system:

1. The pressure relief system shall be designed to depressurize the primary system in the following conditions:

a. In case of primary overpressure, the safety valves shall open to eliminate the overpressure and reclose once the overpressure condition terminates.

b. Redundancy of the primary pressure relief system may be required for investment protection reasons.

\subsubsection{Reactor Support Systems}

\subsubsection{Shutdown Cooling System}

The following are the required functions of the Shutdown Cooling System (SCS):

1. Transport core residual and decay heat from the reactor system to the environment when the reactor system is shut down and the PHTS is not operational. The helium primary coolant may be pressurized or depressurized.

2. Transport core residual and decay heat from the reactor system to the environment when the helium primary coolant is depressurized during reactor core refueling operations.

3. Transport core residual and decay heat from the reactor system to the environment when the helium primary coolant is depressurized during scheduled maintenance of core, vessel, and internal components.

4. Transport core residual and decay heat from the reactor system to the environment when the helium primary coolant is depressurized during certain potential unscheduled maintenance or repair activities. 
5. Support cooling of the IHX, where applicable and as needed, and potentially for other components when the PHTS is not operating.

6. Limit core bypass flow through its components during PHTS operation.

7. Retain helium and radionuclides within the parts of the SCS comprising the primary Helium Pressure Boundary (HPB).

8. Limit the ingress of potential contaminants into the primary helium circuit from components of the SCS external to the primary HPB.

The following requirements are placed on the SCS:

1. The SCS shall retain helium and radionuclides within the parts of the SCS comprising the primary HPB.

2. The SCS shall limit the ingress of potential contaminants into the primary helium circuit from components of the SCS external to the primary HPB.

\subsubsection{Reactor Cavity Cooling System}

The following are required functions of the Reactor Cavity Cooling System (RCCS):

1. Protect the reactor cavity concrete structure, including the support structures of the reactor pressure vessel, from overheating during all modes of operation

2. Provide an alternate means of reactor core heat removal from the reactor system to the environment when neither the PHTS nor the SCS is available.

The following requirements are placed on the RCCS:

1. The RCCS shall operate continuously and maintain reactor cavity concrete temperatures less than $\left[90^{\circ} \mathrm{C}\right]$ during normal operations and less than $\left[150^{\circ} \mathrm{C}\right]$ for off-normal events (short term).

2. The RCCS shall be designed to operate through the utility/user duty-cycle events for the number of cycles specified [TBD] plus those events and even combinations determined to be required by plant transient analysis.

3. Inaccessible parts of the RCCS shall be designed for an operating life of 60 years.

4. The need for access to individual components during normal plant operation and under accident conditions shall be considered in developing building and component arrangements.

5. The RCCS shall be designed to meet availability/investment protection requirements.

6. The RCCS shall be designed to accommodate continuous operation at any power level up to $100 \%$ of rated power.

7. Where cost effective, the design of the RCCS shall incorporate features required to implement online surveillance and performance monitoring.

8. The design of the RCCS shall incorporate those features required to accomplish ISI activities within the time and scheduling constraints imposed by the allotted design planned outage time.

9. The RCCS shall be required to operate continuously in all plant states, including shutdown following loss of forced reactor cooling by the PHTS and SCS with simultaneous loss of pumped circulation of RCCS cooling water, where applicable, and an SSE.

10. All components and piping of the RCCS shall be designed against seismic loads. 
11. All components and piping inside the reactor building, including the connections for emergency water supply (fire brigade), shall be designed against external events (e.g., aircraft crash or pressure waves).

\subsubsection{Fuel Handling Systems}

The following are the required functions of the Fuel Handling System (FHS):

1. Remove and replace fuel from the reactor core

2. Prepare new fuel for use in the reactor core

3. Transfer spent fuel to storage

4. Minimize new and spent fuel inventories in the FHS, possibly through geometric constraint

5. Minimize storage of new fuel at new fuel loading area subject to operability constraints

6. Simplify the FHS to minimize possibility of hold-up or diversion and facilitate inspection

7. Minimize dry fuel transportation route from power block to long-term storage facility. The following are the requirements placed on the FHS:

1. For the prismatic reactor design during reactor shutdown, the FHS shall receive new and irradiated fuel, reflector blocks, and other core elements, to include from the spent fuel storage system, and place them in the reactor vessel, physically replacing and restacking the core.

2. For the pebble bed reactor design, the FHS shall be developed such that the fuel pebbles are circulated through the core to effect online plant refueling.

3. The FHS shall provide shielding to protect workers from radiation during certain fuel handling operations, as applicable.

4. The FHS shall limit the ingress of potential contaminants into the primary helium circuit from components of the FHS external to the primary HPB.

5. For the prismatic reactor design, the FHS shall be designed to accomplish plant refueling within a time interval specified in planned outage allocations.

\subsubsection{Spent Fuel Cooling System}

The following is the required function of the spent fuel cooling system:

1. Actively remove decay heat from the spent fuel elements within their storage containers and transfer the heat to a secondary coolant.

The following requirements are placed on the spent fuel cooling system:

1. The spent fuel cooling system shall be designed to continuously remove and transfer [TBD MWt] of heat absorbed by the cooling water at ambient atmospheric conditions.

2. The spent fuel cooling system shall be designed to operate continuously whenever spent fuel is located in storage.

3. Water quality requirements shall be maintained at all times. 


\subsubsection{Nuclear Island Cooling System}

The following is the required function of the nuclear island cooling system:

1. Remove heat from the reactor plant components by way of a circulating coolant system and transfer heat to an ultimate heat sink.

The following requirements are placed on the Nuclear Island Cooling System:

1. The nuclear island cooling system shall serve the needs of the reactor and its associated components at all times under full-power operating conditions.

2. System makeup shall be provided from the plant Water Supply Treatment System.

3. Redundant components shall be provided for the nuclear island cooling system, as needed, to support continuous operation of the reactor and to provide for online maintenance of the cooling system components.

\subsubsection{Helium Service System}

The following are the required functions of the helium service system:

1. Remove chemical and particulate contaminants from the primary coolant to maintain specified values

2. Supply purified helium to systems filled with helium

3. Remove helium from the primary system and the helium-filled supporting systems and store in a gas store for purified helium

4. Accept helium from helium-filled auxiliary and supporting systems during depressurization activities and, possibly, store radioactively contaminated helium

5. Evacuate primary systems and helium supporting systems

6. Maintain chemical contaminants within required concentration bands.

\subsubsection{Radioactive Waste and Decontamination System}

The following are the required functions of the radioactive waste and decontamination system:

1. Provide for collecting, storing, processing, and monitoring radioactive (or potentially radioactive) liquid and gaseous waste, including various forms of solid waste generated within the plant

2. Provide equipment and procedures to remove radioactive surface contamination from components, as necessary, to facilitate control and minimize migration of radioactive contamination and to limit personnel exposure to radionuclides.

The following requirements are placed on the radioactive waste and decontamination system:

1. The radioactive waste and decontamination system shall collect radioactive and potentially radioactive floor and equipment liquid runoff. These waste streams shall be routed to the liquid radioactive waste subsystem.

2. Provisions shall be included to reduce activity levels contained in liquid effluent.

3. Radioactive liquid waste system components shall be redundant to provide for both system reliability and online maintenance.

4. The gas waste portion of the radioactive waste system shall have sufficient storage capacity to allow for radioactive decay prior to release. 
5. Decontamination equipment shall be skid mounted. Each decontamination skid shall provide steam, wash water (including detergent and/or additives), rinse water, drying air, and vacuuming service.

6. Decontamination system waste shall be collected locally and routed to the appropriate radioactive waste systems.

7. All radioactive waste generated within the facility shall be collected, monitored, treated, and processed onsite prior to shipment offsite.

\subsubsection{Component Handling System}

TBD

\subsubsection{NHS Protection System}

The following is the required function of the protection system:

1. Maintain plant parameters within acceptable limits established for DBAs.

The following are requirements placed on the protection system:

1. The protection system shall implement the relevant monitoring, analysis, and actuation functions necessary to reach the controlled state in case of abnormal events.

2. The protection system shall provide redundant, fail-safe protective functions.

3. The protection system shall remain operable or fail-safe during credible external events.

\subsubsection{NHS Control System}

TBD

\subsubsection{NHS Control Room and Operator Interface System}

The following requirements apply to the NHS control room and operator interface system:

1. The NGNP facility design shall permit the operators to take control of the reactor and support processes from within a single integrated control room using the manual mode at any time.

2. The control room shall remain operable and capable of occupation during credible external events.

3. TBD for additional control room and operator interface requirements, such as human factors, protection in DBAs, etc.

\subsubsection{NHS Monitoring System}

TBD

\subsubsection{Startup and Decay Heat Removal System}

TBD

\subsubsection{Other NHS Systems}

TBD 


\subsection{Requirements Applicable to Heat Transport System}

\subsubsection{Primary Heat Transport System}

The following is the required function of the PHTS:

1. Transfer heat from the reactor core to the secondary circuit.

The PHTS shall be designed with the following requirements:

1. Pure helium shall be used in the PHTS.

2. The following parts of the PHTS shall be replaceable: TBD.

\subsubsection{Main Helium Circulator}

The following is the required function of the Main Helium Circulator (MHC):

1. Control the flow of helium to match the heat generation of the reactor core with the heat removal of the PHTS.

The MHC shall be designed with the following requirements:

1. The MHC shall be driven by electrical motors capable of rated and variable speeds.

2. Bearing design shall preclude contaminant (e.g., lubricating product) ingress in the primary circuit.

3. Thermal insulation shall be required to protect the internal components by reducing heat migration due to primary system temperatures.

4. The MHC shall be designed with a minimum lifetime of 10 years.

5. The MHC shall be designed with hydraulic characteristics as stable as possible over the required speed range without distinctive reversal points and without pronounced peak.

6. The MHC shall maintain primary pressure boundary integrity.

\subsubsection{Hot Duct Assembly (where applied)}

The following is the required function of the Hot Duct Assembly (HDA):

1. Channel high-temperature helium from the reactor core outlet plenum to the IHX inlet. The following shall be requirements placed on the HDA:

1. Radial keys shall provide a radial support during operating and seismic conditions.

2. The HDA shall provide helium leak tightness at each end (with core support structure and IHX).

\subsubsection{Intermediate Heat Exchanger (IHX) (where applied)}

The following are the required functions of the IHXs:

1. Transfer heat from the primary loop to the secondary loop during all normal conditions and between various power levels and certain accident conditions

2. Separate the primary loop from the secondary loop during all normal and abnormal conditions and during accident conditions for a specified time.

The IHX shall be designed with the following requirements: [TBD] 


\subsubsection{Secondary Gas Isolation Valves (where applied)}

The following is the required function of the secondary gas isolation valves:

1. Provide isolation between the primary and secondary circuits during maintenance or abnormal conditions (if required).

The following requirements are places on the secondary isolation valves:

1. The secondary gas isolation valves shall accommodate a pressure differential of [5-9 $\mathrm{MPa}$.

2. The secondary gas isolation valves shall be designed to maintain primary pressure boundary integrity.

3. The secondary gas isolation valves shall be designed to have a maximum leakage rate when shut of [TBD].

\subsubsection{Steam Generator (SG) (where applied to primary circuit) ${ }^{\mathrm{C}}$}

The following is the required function of the SG, when used in the primary loop:

1. TBD (will contain similar requirements to the IHX, plus a probable requirement for the primary fluid to flow in the shell side of the SG).

\subsubsection{Secondary Heat Transport System (where applied)}

The following are the functions of the secondary heat transport system:

1. Provide hot helium to the secondary heat process user, such as steam generator, hydrogen production plant, or other component, and receive the circulating helium at a lower temperature from the secondary heat process.

2. Provide hot helium to the PCS and receive the circulating helium at a lower temperature from the PCS.

\subsubsection{Secondary Helium Purification System}

The following are the functions of the secondary helium purification system:

1. Process a side-stream of helium from the Secondary Heat Transport System to remove chemical and radioactive impurities

2. Provide for tritium removal as required to meet tritium transport limits to plant effluents and products.

\subsection{Requirements Applicable to Power Conversion System}

The following is the required function of the PCS:

1. Convert energy from the PHTS into electricity for distribution on the commercial gird.

The following are the requirements placed on the PCS:

1. The NGNP PCS shall be connected to a local public transmission line for external distribution and sale of [250-300] MWe.

c. When an SG is used in a primary loop, as is currently proposed for the reference configuration containing the Prismatic Block reactor, there are a number of additional required PASSCs which have not yet been accounted for in this SRM. These include process steam, moisture monitoring systems, automatic SG dump systems, SG and reactor pressure vessel drains, and additional reactor trip features in the overall instrumentation and control (I\&C) system. 
2. The NGNP PCS shall produce electricity at $60 \mathrm{~Hz}$.

3. The NGNP PCS shall be designed and sized to produce electricity at commercial scale using $100 \%$ of the NGNP thermal energy from the reactor.

4. The NGNP electrical output shall be delivered to the operating utility at the low-voltage bushings of the main power transformer.

\subsubsection{Steam Turbine and Generator}

The following is the required function of the steam turbine and generator:

1. Produce electricity using steam.

The following are the requirements placed on the steam turbine and generator:

1. The steam turbine and generator shall be designed for superheated steam at a pressure of [TBD] and temperature of [TBD] at the turbine throttle.

2. The steam turbine and generator shall be designed with a single shaft.

3. The turbine shall be designed for main steam temperature variations of up to [TBD].

4. The steam turbine generator rating shall be $[\mathrm{TBD}]$.

\subsubsection{Generator Cooling System}

TBD

\subsubsection{Main Feed-Water System}

The following are the required functions of the main feed-water system:

1. Deliver feed water to the steam generator at the specified temperature, pressure, flow rate, and water chemistry

2. Provide storage to accommodate process fluid surge and volume fluctuations

3. Provide isolation of the feed water to prevent water inflow to a failed steam generator.

\subsubsection{Main Steam System}

The following is the required function of the main steam system:

1. Convey steam from the steam generator outlet nozzles to the inlet nozzles of the high-pressure turbines.

\subsubsection{Main Condensate System}

TBD

\subsubsection{PCS Control and Instrumentation System}

TBD 


\subsection{Requirements Applicable to Hydrogen Production Plant (if and when coupled with NGNP)}

\subsubsection{Hydrogen Production Plant Parameters and Performance}

The following are the parameters and performance requirements for the hydrogen production plant:

1. The hydrogen production plant shall receive process helium at temperatures up to $800^{\circ} \mathrm{C}$ and utilize heat at a rate of up to [TBD MWth] in the production of hydrogen.

2. The hydrogen production plant process efficiency shall be no less than [ $40 \%$ higher heating value].

\subsubsection{Hydrogen Production Plant Configuration}

The following are the requirements for the hydrogen production plant configuration:

1. The hydrogen production plant shall be physically separated from the remainder of the NGNP consistent with commercial plant economic and risk tradeoffs.

2. The interfaces between the hydrogen production plant and the remainder of the NGNP shall be designed to ensure that failures or upset conditions in the hydrogen production plant do not result in failures or adverse impacts to the remainder of the NGNP facility.

3. The interfaces between the hydrogen production plant and the remainder of the NGNP shall be designed to ensure that failures or upset conditions in the NGNP facility do not result in failures or adverse impacts to the hydrogen production plant.

4. The hydrogen production plant shall provide for storage of feedstock (e.g., water and makeup chemicals), as required.

5. The hydrogen production plant shall include all necessary pretreatment or conditioning of readily available raw materials needed for the specific hydrogen process (e.g., water treatment).

6. Hydrogen produced in the hydrogen production plant shall be made available for distribution.

7. No central storage shall be included at the hydrogen production plant other than buffer storage, as required for efficient operations. Storage of hydrogen will provide for pressure relief, venting, valving, instrumentation, and maximum allowable quantities to limit postulated conflaration.

8. The oxygen by-product gas shall have purity levels consistent with current industry standards for bulk oxygen applications. Provisions shall be included for the purification, cooling, and venting or shipping of the oxygen by-product.

9. The hydrogen delivery pressure shall be [TBD MPa].

10. The hydrogen product gas shall have purity levels consistent with current industry standards for bulk hydrogen applications.

11. The interface system between the hydrogen production plant and the remainder of the NGNP shall be designed to ensure that tritium migration into the hydrogen production plant will be limited, such that the maximum amount of tritium released to the hydrogen production plant does not exceed [TBD] standards.

12. The total concentration of radioactive contaminants in the hydrogen product gas and associated hydrogen production systems shall be minimized to ensure that worker and public dose limits do not exceed NRC regulatory limits. 


\subsubsection{Hydrogen Production Plant Waste}

The following are the requirements for the hydrogen production plant waste:

1. The hydrogen production plant design shall be such that there is a disposal path for all waste. Hazardous waste streams identified in 40 CFR 261.3 shall be disposed of accordingly.

2. A means of disposing (such as flaring) of out-of-specification hydrogen product during upsets or startup/shutdown shall be included.

\subsubsection{Hydrogen Production Plant Safety}

Configuring the hydrogen production plant as required by Section 4.6.2 will eliminate the need for active control of the hydrogen process in the NRC operating license. The following are other requirements for the hydrogen production plant safety:

1. The hydrogen production facilities, including the conversion, storage, and distribution systems, shall comply with the requirements of 29 CFR $1910.103,{ }^{7}$ Occupational Safety and Health Standards, Subpart H - Hazardous Materials, Hydrogen.

2. In the event that the hydrogen production plant also produces and stores significant quantities of oxygen, the requirements of 29 CFR 1910.104, "Oxygen," shall also be applied.

3. The design, operation, and maintenance of the hydrogen production plant shall comply with 29 CFR 1910.119, "Process Safety Management of Highly Hazardous Chemicals."

4. Standby power to the hydrogen production facility ventilation, treatment systems, temperature controls, alarms, detection systems, and other electronically operated systems shall be provided in accordance with National Fire Protection Association (NFPA) requirements.

5. Heat exchangers and/or steam generators shall meet the applicable pressure vessel requirements in the ASME B\&PV Code.

6. Design of piping and storage systems will prevent electrostatic discharge and equipment failures from acoustically induced fatigue and hydrogen embrittlement.

\subsubsection{Hydrogen Production Plant Reliability and Availability}

\subsubsection{Capacity Factor}

The following is the requirement for the hydrogen production plant capacity factor:

1. Excluding NGNP mission-specific outages for inspection and testing, the hydrogen production plant design capacity factor for hydrogen production averaged over the plant lifetime shall be at least $[\mathrm{TBD} \%]$ when modeled with equipment mean time to failure and mean time to repair data for the same or similar systems and/or components.

\subsubsection{Planned Outages}

The following is the requirement for the hydrogen production plant planned outages:

1. Excluding NGNP mission-specific outages for inspection and testing, the capacity factor loss due to hydrogen production plant planned outages averaged over the plant lifetime shall be no greater than [TBD \%], including all planned inspection and maintenance activities that must be accomplished with the hydrogen production plant shutdown. 


\subsubsection{Hydrogen Production Plant Investment Protection}

The following is the requirement for the hydrogen production plant investment protection:

1. Excluding NGNP mission-specific outages for inspection and testing, the calculated capacity factor loss due to unplanned hydrogen production plant outages averaged over the lifetime of the plant shall not exceed [TBD. \%].

\subsubsection{Hydrogen Production Plant Maintenance and In-Service Inspection}

\subsubsection{Hydrogen Production Plant Maintenance Requirements}

The following are the requirements for the hydrogen production plant maintenance:

1. The hydrogen production plant shall be designed to allow all components to be removed, replaced (if necessary), and reinstalled.

2. The hydrogen production plant design shall include provisions for monitoring equipment status, configuration, and performance and for detecting and diagnosing malfunctions as a basis for predictive maintenance plans and decision-making.

3. The hydrogen production plant design shall provide storage facilities for an adequate amount of spare parts as determined by a preventive maintenance and facility availability plan.

4. Hydrogen detectors, relief valves, alarms, and isolation valves required for safety will be designed for periodic testing and calibration.

\subsubsection{Hydrogen Production Plant Operational Inspection}

The following is the requirement for hydrogen production plant operational inspection:

1. The hydrogen production plant design shall provide access to the pressure boundary to permit operational inspection as required by appropriate sections of the ASME B\&PV Code.

\subsection{Requirements Applicable to Balance of Plant}

\subsubsection{Cooling Water Systems}

TBD

\subsubsection{Liquid and Gas Supplies}

TBD

\subsubsection{Piping Systems}

TBD

\subsubsection{Electrical Systems}

The following are the required functions of the electrical systems:

1. Deliver power generated by the plant to the offsite transmission network

2. Take power from the off-site transmission network for various plant operations, including startup 
3. Provide backup power to select auxiliaries when the plant power units and off-site power are not available.

4. Deliver primary and backup power to the hydrogen production process.

5. Distribute stable electrical power to plant components at required voltages, amperages, frequencies, and

\subsubsection{High Voltage Power System}

TBD

\subsubsection{Medium Voltage Power System}

TBD

\subsubsection{Low Voltage Power System}

TBD

\subsubsection{Backup Power System}

TBD

\subsubsection{Direct Current/Uninterruptible Power Supply System}

The following is the required function of the Direct Current (DC)/Uninterruptible Power Supply (UPS) System:

1. Provide a stored energy source for the all plant direct current loads.

\subsubsection{Grounding System}

The following are the required functions of the grounding system:

1. Protect personnel and equipment from system faults and lightning strikes

2. Minimize electrical noise in signal cables.

\subsubsection{Communication and Lighting}

The following are the required functions of communication and lighting:

1. Provide intraplant communications

2. Provide internal and external lighting.

\subsubsection{Plant Control Room System}

The following is the required function of the plant control room system:

1. Provide an interface between plant operators and each of the necessary systems within the plant.

\subsubsection{Plant Mechanical Services System}

TBD 


\subsubsection{Fire Detection and Suppression System}

The following are the required functions of the fire detection and suppression system:

1. Rapidly detect and annunciate the presence and location of combustion by-products or the presence of fire within the plant and the hydrogen production process

2. Control and extinguish fires that do occur

3. Provide protection for PASSCs such that the performance of safety functions is not prevented.

\subsubsection{Communications System}

The following is the required function of the communications system:

1. Provide plant to offsite communications.

\subsubsection{Safeguards and Security System}

The following is the required function of the Safeguards and Security System:

1. Provide physical protection of the plant

\subsubsection{Plant I\&C and Protection}

TBD

\subsubsection{NGNP Supervisory and Control System}

TBD

\subsubsection{Site and Civil Works}

TBD 


\section{REFERENCES}

1. Public Law 109-58, "Energy Policy Act (EPAct) of 2005," Department of Energy, Office of Energy Efficiency and Renewable Energy, August 2005.

2. NGNP Preliminary Project Execution Plan, PLN-2825, Rev. 0, September 30, 2008.

3. Next Generation Nuclear Plant - High Level Functions and Requirements, INEEL/EXT-03-01163, Idaho National Laboratory, September 2003.

4. Independent Technology Review Group, Design Features and Technology Uncertainties for the Next Generation Nuclear Plant, INEEL/EXT-04-01816, Idaho National Laboratory, June 30, 2004.

5. Next Generation Nuclear Plant Project (NGNP) Preliminary Project Management Plan, PLN-2489 (INL/MIS-08-14339), Rev. 2, Idaho National Laboratory, June 2008 (NOTE: suspended by Rev. 3, October 2008).

6. FR Doc E8-24268, "Policy Statement on the Regulation of Advanced Reactors," Federal Register, October 14, 2008 (NRC Document ID NRC-2008-0237-0010, effective date November 13, 2008).

7. 29 CFR 1910.103, "Occupational Safety and Health Standards," Subpart H, "Hazardous Materials - Hydrogen," Code of Federal Regulations, Office of Federal Register, January 2009.

8. 29 CFR 1910.104, "Occupational Safety and Health Standards," Subpart H, "Hazardous Materials — Oxygen,” Code of Federal Regulations, Office of Federal Register, January 2009.

9. 29 CFR 1910.119, "Occupational Safety and Health Standards," Subpart H, "Hazardous Materials - Process safety management of highly hazardous chemicals," Code of Federal Regulations, Office of Federal Register, January 2009.

11. Meeting Minutes, "Next Generation Nuclear Plant Project, Senior Advisory Group Meeting, Reference Configuration, Crystal City, VA, October 28, 2008," Rev. 1 of Minutes, dated January 28, 2009 